Culture et histoire dans l'espace roman

\title{
Mutantes. Cuerpo y relato en la obra de Mario Bellatin
}

\section{Gersende Camenen}

\section{(2) OpenEdition}

\section{Journals}

Edición electrónica

URL: https://journals.openedition.org/cher/8410

DOI: $10.4000 /$ cher. 8410

ISSN: 2803-5992

\section{Editor}

Presses universitaires de Strasbourg

\section{Edición impresa}

Fecha de publicación: 30 junio 2010

Paginación: 173-183

ISBN: 978-2-35410-007-0

ISSN: 1968-035X

\section{Referencia electrónica}

Gersende Camenen, «Mutantes. Cuerpo y relato en la obra de Mario Bellatin», reCHERches [En línea], 4 2010, Publicado el 15 diciembre 2021, consultado el 25 enero 2022. URL: http:// journals.openedition.org/cher/8410 ; DOI: https://doi.org/10.4000/cher.8410

\section{(c) () (ㅇ)}

Ce(tte) œuvre est mise à disposition selon les termes de la Licence Creative Commons Attribution -

Pas d'Utilisation Commerciale - Partage dans les Mêmes Conditions 4.0 International. 


\title{
Mutantes. Cuerpo y relato en la obra de Mario Bellatin
}

\author{
GeRSENDE CAMENEN \\ Université de Paris VIII - Universidad de Buenos Aires
}

$\mathrm{n}$ el panorama actual de la literatura latinoamericana, la obra de Mario
Bellatin surge como un proyecto original y arriesgado. Bellatin cultiva una narrativa que borra los límites entre realidad y ficción, tejiendo tramas fragmentadas y construyendo personajes inestables. El aporte más singular de Bellatin es sin duda la forma de representar el cuerpo físico. El cuerpo es un actor esencial de sus narraciones y es una constante de su escritura que no ha pasado desapercibida para ningún lector. Las observaciones de quienes han reseñado sus libros en relación con el tema (en realidad todos, de una forma u otra están relacionados con el tema) se pueden resumir en una frase: el autor es obsesionado por la presentación de cuerpos deformados que se mueven en un universo frío, de atmósfera enrarecida, carente de emoción. Bellatin sería para la crítica el estilista de los cuerpos enfermos, maltrechos y dolorosos; el que contempla en las miniaturas que compone en esteta decadente, las múltiples flores (Flores, 2001) del mal manifestarse en el cuerpo físico (hablar de "cuerpo humano" parece aquí extraña y totalmente desatinado).

Dada la importancia del tema del cuerpo en la obra de Bellatin y sus numerosos aspectos, delinearé las regiones de este mapa de lo anómalo dibujado por sus libros. Insistiré luego sobre un aspecto esencial y que hace toda la originalidad de la escritura de Bellatin, el lazo fuerte, casi simbiótico que se da entre el cuerpo físico y el cuerpo textual. Para ello, veremos cómo 
el relato en los textos de Bellatin se ve sumido a un verdadero trabajo de desarticulación. Por fin dicho trabajo de fragmentación y rearticulación se hace no solamente a nivel de cada libro, sino también a nivel de la obra entera, veremos así cómo se configura un nuevo cuerpo que el propio autor construye de manera muy consciente a través de diferentes estrategias, paralelamente a la elaboración de su figura de autor en la cual el cuerpo desempeña también un papel clave. Dicho de otro modo, la cuestión del cuerpo en el caso Bellatin, se encuentra en un cruce teórico esencial puesto que baraja las nociones eminentemente problemáticas de relato, obra y autor. El presente artículo intenta mostrar la dinámica que reúne estos tres elementos dentro de un verdadero sistema. Es, pues un texto más bien programático que apunta pistas de lectura de una obra que se presenta como un todo cuidadosamente construido por el autor.

\section{Un mapa de lo anómalo}

En los libros de Bellatin, el protagonismo exclusivo y excluyente le corresponde al cuerpo. Enfermo, mutilado, mutante, aparece como un reto a la vez exuberante y sumamente inquietante a cualquier idea de normalidad. A lo largo de sus libros, Bellatin escribe la épica de esta verdadera catástrofe que es el cuerpo, dibuja un mapa del deterioro físico que hace triunfar la anormalidad, la "verdad de los defectos" como dice un anciano en Flores (2001). Se lee en el mismo libro que "Las mutaciones genéticas propias de cada raza se manifiestan en algunos momentos con más fuerza que en otros [...] y al final de este proceso suele reconocerse que lo anormal está llamado a convertirse en lo esperado». Queda claro que los cuerpos extraordinarios forman parte de un universo literario en el cual lo anómalo es la regla y no la excepción. Esta normalización de lo singular se evidencia más explícitamente en La escuela del dolor humano de Sechuán donde «los miembros del equipo tuvieron entonces que volver por sus propios medios al poblado de origen y encontrarse con los demás integrantes de una comunidad donde la falta de dedos en la mano derecha era el rasgo en común».

En esta épica del cuerpo, lo anómalo aparece a cada vuelta de página. Bellatin se acerca a todos los ámbitos de lo anómalo, de lo que comúnmente provoca malestar, extrañeza, inquietud o cierta curiosidad morbosa. Crueldad, malos tratos, sexualidad ambigua, transexualidad, prostitución, exhibicionismo y voyeurisme, enfermedad, deformaciones, rarezas físicas, parricidio, infanticidio, incesto, ritos corporales y funerarios extraños, 
acondicionamiento disciplinar, nada que pertenezca al continente oscuro de lo anómalo, de lo heterodoxo parece faltar en los breves textos del autor.

Si bien como lo veremos a continuación, los textos de Bellatin desafían la definición de un sentido estable, los textos parecen ofrecer pistas de interpretación. Los que se inclinan hacia una lectura alegórica pueden considerar las aventuras y desventuras del cuerpo como reflejos del imaginario contemporáneo.

Algunas líneas narrativas nos permiten incluso definir dentro de la obra series o ciclos en los que el cuerpo es el lugar de reflexión sobre la sociedad, política en el sentido amplio de la palabra. Evocaremos dos de estos ciclos, en los que la cuestión del cuerpo es central. Así una primera serie se compone de Damas Chinas, Salón de Belleza que guardan lazos con el mundo extraliterario puesto que las referencias a un mundo regido por reglas patriarcales, marcado por el machismo parecen ubicar sus historias respectivas en el mundo latinoamericano. Damas chinas deshace con una eficacia vertiginosa y escalofriante la sacrosanta relación padre-hijo, dejando sospechar que el padre, un ginecólogo, exitoso y mujeriego, mató a su propio hijo. La familia aparece como un lugar frío y perverso, un ente anormal que oprime al individuo, destruyendo su libertad y su poder de imaginación. Cortar con cualquier residuo de lazo con esta monstruosidad, este microcosmos que refleja la opresión social y estatal es la decisión más sana, parece sugerir Bellatin, con un radicalismo que no desmentiría el antipsiquiatra Laing. En Salón de belleza, la familia es el engranaje de una sociedad opresiva que expulsa a los enfermos del sida que encuentran asilo en un salón de belleza convertido en moridero. En esta familia no convencional - fundada por un estilista transformado en enfermero que enfrenta la muerte y el dolor sin compasión pero eficientemente - el autor aborda la muerte despojándola de cualquier convención religiosa o moral.

Otro ciclo es el constituido por Canon perpetuo, Poeta ciego y La escuela del dolor humano de Sechuán que se han leído como una crítica a las sociedades totalitarias que se podrían asociar con Cuba, la antigua Unión Soviética y China, respectivamente. Estos textos presentan unos mundos jerarquizados por un poder que nunca se identifica abiertamente pero que influye de manera oculta y decisiva sobre el comportamiento (absurdo muchas veces) de los personajes. El acercamiento de Bellatin al tema es interesante y turbador, no cae en una división sencillista entre buenos y malos puesto que los excesos autoritarios encuentran una ciega sumisión de las mayorías. Es más, los textos indagan en las complejas relaciones 
entre placer y dolor. Así, La escuela del dolor humano de Sechuán, texto inicialmente pensado para una representación teatral, supuestamente basado en los textos de un tal Lin Pao, autor ficticio de obras teatrales "descubierto" por Brecht, se ofrece como una serie de cuadros sobre diferentes tormentos, con acotaciones precisas para la representación del dolor mezclado de goce de quienes operan y padecen las torturas chinas.

Con su acercamiento crítico a la familia o al poder político, los libros de Bellatin parecen inscribirse en un contexto literario latinoamericano que propone un trato corporal diferente al tradicional - donde el cuerpo no es un problema puesto que se ignora o se da por sentado, pensamos en la literatura gay, feminista o en la literatura de las dictaduras del Cono Sur donde el cuerpo politizado, marcado por las huellas del poder figura en el centro del discurso literario. Es cierto que los libros de Bellatin comparten con estas corrientes un interés marcado por el cuerpo que no se considera como un apéndice del personaje, un derivado del desarrollo psicológico sino como un ente independiente y desconcertante. Pero a diferencia de estas corrientes, los cuerpos en Bellatin no son politizados en forma explícita. Bellatin los coloca en el centro de lo narrado, borrando la figura de unos personajes desprovistos de biografía, vaciados de toda singularidad (algunos tienen un nombre función como la Madre, la Amiga, cargado de un peso semántico preexistente que sin embargo se subvierte en el proceso de lectura) y es a partir de la fragmentación de estos cuerpos singulares cómo se genera su discurso, igualmente singular e inquietante. Bellatin hace del cuerpo un problema, un sitio de exceso e ilegibilidad radical. Para analizar este lazo simbiótico entre cuerpo físico y cuerpo textual conviene detenerse en las características del relato en los libros de Bellatin.

\section{Relato fragmentado y suspensión del sentido}

Resumir un libro de Bellatin es un verdadero reto. No es el tamaño de los libros lo que impide el ejercicio básico de cualquier lector: los libros de Bellatin son más bien minimalistas tanto en cuanto a su extensión como a los recursos empleados. Pero tanto la lógica absurda que los gobierna como la profusión de historias sin desenlace dificultan el relato. En los primeros textos publicados, como Salón de belleza, el relato se centra en una historia. Pero no la cuenta de manera lineal y es casi imposible encontrar la lógica temporal que sigue, puesto que el relato avanza adelantándose y retrocediendo de manera permanente. El texto se divide en una serie de 
párrafos que no relatan la historia de manera continua y dan la impresión de ser textos aislados que se podrían leer de manera autónoma.

Esta impresión, cultivada por el autor, se impone en los libros siguientes. Damas chinas presenta dos relatos, uno cuenta la vida del ginecólogo y otro, extraño, se centra sobre la figura del hijo hidrocefálico de una de sus pacientes. Los vínculos entre los dos textos no son a primera vista evidentes pero el discurso del niño, obsesivo y circular, sugiere la culpabilidad del ginecólogo infanticidio nunca asumida en el otro texto. En los libros siguientes, el proceso de fragmentación se radicaliza hasta que la unidad textual se reduzca muchas veces a la propia frase. Y Bellatin lleva la lógica a su término con los doscientos sesenta fragmentos numerados de Lecciones para una liebre muerta, pequeños relatos que se alternan, saltan en el tiempo y juegan unos con otros para construir de alguna manera una enigmática narración que los acepta a todos como partes alusivas.

La fragmentación es pues el principio que rige la composición de los libros, como un movimiento entrópico controlado que deshace la forma tradicional del relato y la apariencia misma del texto. Queda claro que lo que importa no es necesariamente lo que ocurre sino cómo se manipula y estructura el material presentado. Y el material puede ser tanto textual como visual. En efecto, al añadir imagen al texto en Shiki Nagaoka, Jacobo el Mutante y Perros héroes, Bellatin da un paso adicional en su indagación sobre la naturaleza de la ficción y la deconstrucción del relato. En los textos mencionados, la fotografía se utiliza de manera vanguardista o posmoderna si se quiere: la imagen no se presenta como una prueba de la referencialidad y de la reproducción del significado (el sustituto ideal del effet de réel de los textos realistas) sino como un lugar en el cual la realidad está siempre ausente. Shiki Nagaoka, biografía de un misterioso autor japonés de culto, escritor maldito de pocas obras, incluye al final unas veinte fotografías que tejen un doble discurso. Por un lado coquetean con las reglas del discurso realista, de reportaje cultural o la indagación seudo-universitaria: la fotografía (retratos del autor, de su sobrina y fotos de objetos, lugares utilizados y frecuentados por el autor, de textos escritos por él o dedicados a su obra) se emplea como documento, prueba de la realidad de lo representado, y cumple la misma función que las citas de autores japoneses o la bibliografía de trabajos sobre el misterioso autor. Pero por otro lado las fotografías con sus breves textos enigmáticos se presentan como simulacros que minan la autenticidad de un personaje ficticio. En Jacobo el mutante, novela sobre una novela no existente de un autor real, el judío austriaco Joseph Roth, las fotografías, insertadas 
en el texto, muestran paisajes vacíos y desolados, todo un imaginario de las huellas que resalta la ausencia de los seres y particularmente del cuerpo del personaje principal Jacobo Pliniak, el mutante que desapareció en un lago para luego emerger como una mujer. Las fotografías en este caso, fragmentan el propio texto, cortando la narración y dando un ritmo melancólico a esta historia de numerosos ecos literarios e históricos sobre un escritor judío, errante, hijo perdido de la mittleeuropa.

¿Cómo atribuir un sentido al cuerpo, al texto, objetos atacados en su unidad por un mismo gesto continuamente reafirmado? La fragmentación extrema parece en efecto impedir la búsqueda de un sentido transparente, lleno, de una "visión del mundo" o de "un significado profundo" de los cuerpos y por ende de los textos. Hay en las historias arquitectónicamente construidas por Bellatin una pasión por lo absurdo que pone en tela de juicio la noción misma de representación, empezando por deshacer un objeto, el cuerpo que oscila permanentemente entre realidad y ficción como lo sugiere el juego con las imágenes. Finalmente, los relatos "ilegibles" de Bellatin reflejan la ilegibilidad de los cuerpos, cuerpos en devenir constante, sin orden preexistente (como el cuerpo deleuziano anterior al organismo). $\mathrm{Al}$ relato normal (narrador ubicable, tiempo espacio definido, causalidad respetada) Bellatin sustituye un relato ilegible (narrador oscilante, lazos tenues con contextos espacio-temporales voluntaria y juguetonamente "exóticos" que tienen por efecto desterritorializar lo narrado y alejar al lector de los referentes familiares para acercarlo a la esencia del universo ficticio). En un gesto idéntico sustituye al cuerpo normal (de partes completas, eficaz para el trabajo, bello y sanamente sexuado) cuerpos subversivos e insumisos al canon. Estos cuerpos que no respetan el orden, el juego social con sus normas y límites son ejemplos de la crisis del sujeto cartesiano, de la disolución de sentidos fijos y de verdades absolutas que han estructurado la modernidad. Así se han hecho comparaciones sugerentes de la propuesta de Bellatin con los trabajos del cineasta David Cronenberg y su concepto de la nueva carne (the new flesh) el cuerpo en metamorfosis que fusiona con la máquina, paralelo oportuno en el caso de Bellatin que como se sabe tiene una mano artificial y juega con este estatuto de hombre biónico.

Una pista para entender el lazo simbiótico entre la desarticulación del cuerpo físico y la desarticulación del cuerpo textual se encuentra en Shiki Nagaoka donde el ficticio escritor japonés ofrece un resumen de su obra, como también, implícitamente de la obra de Bellatin, advirtiendo que su novela, escrita en una lengua que no existe, trata de la relación «entre la 
escritura y los defectos físicos [...] y cómo la literatura que de allí surge debe distanciarse de la realidad apelando al lenguaje, en este caso al no-lenguaje».

Si los textos de Bellatin ostentan la disolución del sentido, apelan a un no-lenguaje que no produce significados ¿Qué hacer con las lecturas alegóricas, psicoanalíticas o políticas que hemos evocado brevemente? ¿Son puras ilusiones, delirios hermenéuticos de unos lectores débilmente aferrados al sacrosanto sentido, lectores que no captarían la esencia metafictiva de esta literatura?

He aquí donde radica el juego de Bellatin. Consciente del impulso teleológico y totalizante que orienta al lector, invita a suponer que detrás de cada cuerpo deformado y de cada trama absurda se esconde un terrible secreto que el escritor descubrirá al final. El lector intenta encajar las piezas del rompecabezas, busca el orden original, la conexión secreta entre los elementos caóticos de la narración, o sea intenta armar cuerpos y textos. Y Bellatin lo sigue en este juego, armando trampas. Así Flores, por ejemplo, se abre sobre un texto que da la supuesta clave de lectura del libro. Dice Bellatin :

Existe una antigua técnica sumeria, que para muchos es el antecedente de las naturalezas muertas, que permite la construcción de complicadas esctructuras narrativas basándose en la suma de determinados objetos que juntos conforman un todo. Es de este modo como he tratado de conformar este relato, de alguna forma como se encuentra estructurado el poema de Gilgamesh. La intención inicial es que cada capítulo pueda leerse por separado, como si de la contemplación de una flor se tratara.

Aquí lo que se da es menos una clave de lectura (que en realidad no aclara gran cosa sobre lo narrado) que una descripción perfecta de cómo se construyen los relatos de Bellatin, con pistas siempre falsas, que supuestamente permitirán desentrañar el misterio del texto y que sugieren al lector que tendría que buscar la solución en fuentes literarias o extraliterarias pero siempre exteriores al texto. De paso, este ejemplo es en efecto revelador del uso que hace Bellatin de otras culturas, y en el caso que nos interesa, de sus cuerpos "diferentes": el exotismo es una artimaña narrativa, algo perversa, que juega con la perplejidad que nombres y referencias extranjeras (o también esotéricas y místicas) pueden causar al lector, dándole a entender que la razón por la cual no entiende la totalidad de un texto es su ignorancia sobre la cultura china, japonesa o judía que supuestamente constituye la clave para entenderlo. 
Otra manera de despistar al lector consiste en mezclar verdades perentorias y sutiles interrogaciones, es decir desplegar una retórica que afirma la objetividad, la seguridad del narrador (sintaxis clara, frases breves, adjetivación precisa, quirúrgica) y al mismo tiempo insinúa una profunda duda en el lector con una serie de formulaciones de distanciamiento con lo narrado. Veamos ahora cómo se cierra Flores, con otro texto que pretende dar claves de interpretaciones del libro (con sus temas de predilección, los errores de la ciencia, las relaciones padre-hijo) que el lector acaba de leer, pero con unas formulaciones que no hacen sino mantener un velo de incertidumbre e ironía:

Las preguntas sobre lo que sucede con los mecanismos de información de la ciencia cuando ésta se equivoca, tal vez nunca sean contestadas. Quizá algún filósofo esté preparando una respuesta, esperemos, a la altura de las circunstancias. Habrá que aguardar, no se sabe cuánto tiempo, para escucharla. Mientras tanto, las relaciones entre padre e hijos, entre lo anormal y lo normal en la naturaleza, la búsqueda de sexualidades y religiones capaces de adaptarse a las necesidades de cada unos de los individuos, seguirán su rumbo, como si de una complicada trama sumaria se tratase. Es posible que frente a esto, el lenguaje de las flores sea más expresivo de lo que parece. Confiemos en ello...

Al lector le queda una opción, la de tomarse en serio no tanto los discursos (creyéndose que Bellatin sería un erudito excepcional de las culturas japonesas, chinas o judias y de más, el especialista científico o el amante de los cuerpos deformados) sino el propio juego de la broma vanguardista, es decir ser juguetonamente serio, es decir, contemplar flores y olvidarse de las interpretaciones doctas. Vale para las lecturas alegóricas. El autor las supone, se adelanta a ellas, dejando al lector desprovisto de su supuesta capacidad hermenéutica, sugiriendo que el sentido está siempre siendo desplazado.

Resumamos. Totalitad imposible, des-realización, retórica de la duda : Bellatin sería el perfecto ejemplo del autor posmoderno, deconstruccionista para quien todo tipo de unidad sería pura ilusión y cuyos textos, concebidos como artefactos abiertos que ostentan su proceso de fabricación, encontrarían en el cuerpo deformado, destructurado su perfecta metáfora.

Ahora bien, es interesante ver cómo, a otro nivel, Bellatin vuelve a encontrar cierta unidad, a reconstruir un cuerpo. 


\section{Obra y autor}

Un lector que haya frecuentado la obra de Bellatin puede tener la impresión de que está leyendo o bien siempre el mismo libro, o bien un solo libro, disperso en fragmentos, reescrito, recompuesto libro tras libro. No solamente se repiten los temas (entre otros la sexualidad, el misticismo, la ciencia, las relaciones padre-hijo) sino que claramente se reutilizan pedazos de historias, se da un nuevo desarrollo a argumentos anteriormente escritos. La obra se auto-alimenta, como un gran cuerpo autónomo, una máquina eficaz y algo inquietante. Entre los muchos ejemplos de esta autorreferencialidad, intertextualidad y metaficcionalidad constantes, motores de la escritura, veamos el ejemplo ya evocado de Lecciones para una liebre muerta.

En los doscientos sesenta fragmentos del libro, el lector sigue a un escritor sin nombre (cuya vida en muchos aspectos coincide con la de Bellatin) que cuenta en primera persona que ha conseguido una residencia en una casa para escritores en los Estados Unidos para escribir en silencio y concentración. Habla de sus rituales con las máquinas de escribir, tiene una mano artificial (como Bellatin) que le juega malas pasadas, se hace amigo de un travestí filósofo. Este autor que es y no es Mario Bellatin (el "escritor Bellatin" es también en algún momento de su relato uno de sus personajes) cuenta también la historia de Margo Glantz y de la mujer que insistía en alimentar a la perra de la escritora con hígado crudo y de cómo Margo Glantz (escritora mexicana de origen judío a quien dedicó Jacobo el mutante) inventó un Golem para librarse de ella. En otros fragmentos, sin que nadie se atribuya el relato, se cuenta otra red de historias sobre un poeta ciego, título y personaje de un libro anterior y otras sobre un traductor, personaje que reaparecerá en El Gran Vidrio. Lecciones es claramente una mise en abyme de la obra que el propio autor presenta como un sistema. En Underwood portátil. Modelo 1915, a propósito de su obra, de la escritura, escribe Bellatin:

Con el tiempo se me ocurrió inventar un sistema literario propio, bastante absurdo por cierto, pero que fuera capaz de explicar las frases, una por una, que iban apareciendo libremente en los textos. Lo importante, como ya dije, no eran los contenidos de las historias ni los personajes. Tampoco los libros que fueran creándose a partir de esta manera de trabajar. Lo único que podía tener algún valor, era la conciencia que pudiera alcanzar el sistema de mi invención. Eso me sirvió para escribir por encima de lo que estaba escribiendo, como me gusta de vez en cuando afirmar. Es decir, para no involucrarme realmente con las cosas que se contaban ni con los universos que se iban representando. 
¿Qué hace Bellatin en Lecciones sino demostrar lo que acabamos de leer: que no hay nada digno de contar y que lo que le interesa a él es registrar procesos de recuperación, de presentación y no realmente de representación, en otras palabras, construir un sistema - un cuerpo metafórico - y evidenciar su gesto? En esta dinámica que insiste más en la presentación del proceso que en la representación se inscriben las diferentes facetas, atípicas, de su producción que si bien albergan la escritura como substrato, abren la reflexión sobre la recepción de la palabra escrita. Citemos el interés marcado por el devenir teatral de sus libros (La escuela del dolor humano de Sechuán); el devenir instalación de sus obras, instalaciones visuales en el caso de Perros héroes con su "dossier" de fotografías e instalaciones verbales en la extrema fragmentación de Lecciones o Flores. Y por fin el constante juego con las artes plásticas que inscribe la literatura dentro de un sistema más amplio, donde no es el protagonista central (la liebre de Lecciones remite a uno de los fetiches del artista plástico Joseph Beuys cuyo universo coincide en muchos aspectos con el de Bellatin). La obra de Bellatin se construye a través de estos gestos que abren la literatura, transformando los textos en un cruce de prácticas, integrando al cuerpo físico (de los actores, de los performers) haciendo de la literatura un todo fluido, proteico, en tres dimensiones incluso, todo lo contrario de un todo orgánico.

Falta una pieza sin duda esencial a esta presentación, al "sistema" Bellatin, el autor. La postura de Bellatin, clásicamente posmoderna - o mejor dicho, en el caso de un Bellatin tan irreverente - juega con "la muerte del autor" proclamada por Foucault, lo cual se demuestra a diferentes niveles. Primero en los textos, hay un juego fuerte, permanente con lo autobiográfico hasta el punto de que el escritor Bellatin sea un personaje de sus propios libros, tan inestable como los otros, de identidad proteica, fluida y finalmente siempre desplazada. Luego, la muerte del autor se traduce en esta otra dimensión de la escritura cultivada por Bellatin, la creación de experiencias artísticas que suman ingredientes estéticos a la reflexión sobre la constitución y la recepción de la palabra escrita. En 2003, Bellatin realizó un proyecto-performance, Dobles de escritores, en el cual sustituyó a cuatro autores mexicanos (Margo Glantz, Salvador Elizondo, Sergio Pitol y José Agustín) por cuatro personas, "clones" entrenados por aquéllos por quienes se hacían pasar. Comprobó así su tesis de que toda identidad es un simulacro, es decir, una performance constituida por discursos y demandas aprendidos y repetidos.

Ahora bien ¿qué hace Bellatin cuando juega con su propia biografía, con la imagen de su propio cuerpo (como lo vimos en el caso de Lecciones) sino 
tejer sus propios mitos, armar una máquina de contar desde dentro de su literatura? Más que nunca la obra se lee a través del autor, no directamente desde su biografía pero sí desde la figura de autor cuidadosamente aunque juguetonamente elaborada por el propio escritor. Es probable que el Autor (avatar de Dios en la tierra, sujeto omnipotente que controla su escritura, cuyos textos revelan una "intención" y que finalmente es la fuente de sentido del texto) haya muerto pero el "efecto Bellatin", e incluso el efecto-cuerpo "Bellatin", cuerpo biónico, determinan de manera decisiva la recepción de cada nuevo libro, en un vertiginoso retorno de lo reprimido. Es divertido escucharlo decir en una entrevista que «en Latinoamérica somos víctimas del abuso de la presencia del autor $»$. Bellatin no es presente, es omnipresente como cuerpo, y si lo comprendemos bien, como matriz del propio libroobjeto. En Underwood portátil, se define en efecto como pura pulsión mecánica que inscribe caracteres sobre la página, pura herramienta de la escritura: «En un comienzo creí que el placer, o más bien, la obsesión estaba en apreciar la aparición de las palabras por sí mismas. En ese tiempo comencé a pensar que se perfilaba en mí un auténtico mecanógrafo ».

Finalmente, en esta obra tan conceptual de un autor tan "cerebral", el sujeto, vuelve al primer plano con una escritura que nace de las pulsiones, de la subjetividad absoluta (escritura que se podría definir como Roman o Science fantasmatique para parafrasear al último Barthes, aquél que en La préparation du roman, vuelve al sujeto, aquél que había declarado que la escritura literaria era intransitiva, hace de los afectos del autor, del absoluto del cuerpo la fuente de la escritura). Aunque, en lectores cautelosos y acostumbrados a las trampas de Bellatin podamos empezar a desconfiar de esta escritura, y sospechar que el autor juegue otra vez con el discurso literario y teórico.

\section{Bibliographie}

Barthes, Roland, 2003, La Préparation du roman I et II, Cours et séminaires au Collège de France (1978-1979 et 1979-1980), Paris, Seuil, «Traces écrites». Bellatin, Mario, 2005, Obra reunida, México, Alfaguara. Bellatin, Mario, 2005, Lecciones para una liebre muerta, Barcelona, Anagrama. Bellatin, Mario, 2007, El Gran Vidrio, Barcelona, Anagrama. 